\title{
The Asphalt Pavement Vertical Stress Dynamic State Response under the Moving Load
}

\author{
Jian-hong Gao \\ Architecture and Civil Engineering School,UST Inner Mongolia,Baotou 014010,China \\ gjh76219@163.com
}

Keywords: Moving load, Asphalt Pavement, vertical stress, dynamic state response

\begin{abstract}
Aiming at the common asphalt pavement structure combination, large general finite element software is used to build the three-dimensional model based on the multi-layer elastic system theory. The pavement structure vertical stress $\&$ time curve are analyzed entirely under the moving load. The results show: the node vertical stress still appears tension \& compression status alternately and presents sine curve decreasing after the load acting. It is thus clear that the nodes vertical stress expresses vibration state under the moving load. Passing the same time length after the load acting the node, as the load moves from the front to the rear, the vertical stress of the node is also reduced. Thus, the vertical stress under moving load is more complex than that under static load.
\end{abstract}

\section{Introduction}

The vehicle axis load on the road is heavier and the channel transportation characteristic is clearer along with expressway development quickly and the road transport capability promotion continually. So the road structure layers always appear early part damage: such as push motion, crack, rut etc early damages, not only affecting the pavement normal using but also bringing safety serious hidden trouble to the vehicles. At present the city road and highway design ${ }^{[1-2]}$ in China are all based on elastic layered system under the static load model, and the actual wheel loads are dynamic, the road bearing the vertical vibration and shock \& horizontal effect along with time changing. As the pavement structure itself is sensitive to load time, so the mechanics properties caused from the dynamic load are different greatly from the static model. Using finite element software and the structure dynamics and vibration theory to building the asphalt pavement dynamic load three-dimensional entity model ${ }^{[3-4]}$, the pavement dynamic state response under the moving load is calculated, and the pavement vertical stress under the dynamic load are discussed. So some useful laws can be given and referenced.

\section{Moving load}

The moving load belongs to the dynamics field. Different from the static analysis, dynamic analysis must consider the load change with time and its influence on the damping and inertia. According to structure bearing the load type, dynamic analysis can be roughly divided into the following types: Modal analysis, Spectral analysis, Random vibration analysis and the transient dynamic analysis. The transient dynamic analysis is mainly used for analysis of structure response of load changes with time; ensure that the structure does not appear to damage under impact load. The pavement structure layer mechanical response analysis of moving load is a transient dynamics time course analysis in this paper. 


\section{The finite element model building and interrelated parameters selection}

ANSYS model.The paper chooses multy-layer pavement structure and supposes the material is linear \& elastomeric, shown as Fig.1. The building model cell is three-dimensional hexahedron 8 -node and the model size $(X, Y 、 Z)$ is $3.0 \mathrm{~m} \times 2.0 \mathrm{~m} \times 2.0 \mathrm{~m}$. The boundary: underside UY=0; driving directions is $\mathrm{X}$ direction, and from beginning to end $\mathrm{UX}=0 ; \mathrm{Z}$ direction is the road width and no restriction. The contact condition is entirety continuum. The load ${ }^{[2]}$ is BZZ-100, that is to say the axis heft $100 \mathrm{kN}$, the wheel pressure $0.7 \mathrm{Mpa}$. In addition, this paper uses international units.

Moving load parameters. In this paper, the transient analysis uses FULL method. The design speed $\mathrm{V}=60 \mathrm{~km} / \mathrm{h}$. The scalar parameters are pre defined in order to using the software program design language APDL for programming to realize repeated load. Mainly these parameters include the element unit length in the load moving direction, load velocity, the magnitude of load and passing time by each element.

The program will eventually transform the initial load into nodes load, and become a concentrated load no matter its adding form in the finite element method. So this paper program imposed concentrated load directly to the nodes. According to the international system of units the load should be N, standard axle load should be $100000 \mathrm{~N}$. The concentrated load moves from the first node to the last node with a constant velocity through programming * do and *enddo cycle statement. The load is deleted after the end of each load step, and then it is applied to the next node to solve, in turn forward until the end. Each load step was divided into 5 load step.

The compute model adopts the typical semi rigid pavement structure; specific data are shown in table 1 .

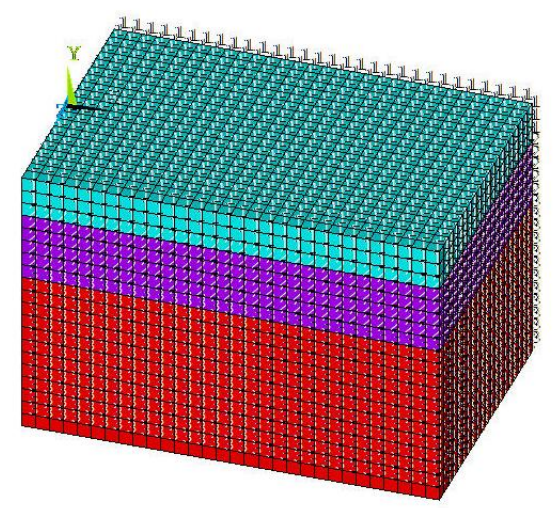

Table 1 pavement structure combination

\begin{tabular}{|c|c|c|c|}
\hline combination & $\begin{array}{c}\text { Modulus and } \\
\text { thickness }\end{array}$ & Poisson ratio & density \\
\hline $\begin{array}{c}\text { Asphalt concrete } \\
\text { surface layer }\end{array}$ & $\begin{array}{c}\mathrm{E} 1=1200 \mathrm{Mpa} \\
\mathrm{h} 1=27 \mathrm{~cm}\end{array}$ & 0.35 & $2400 \mathrm{~kg} / \mathrm{m}^{3}$ \\
\hline $\begin{array}{c}\text { Semi-rigid } \\
\text { layer }\end{array}$ & $\begin{array}{c}\mathrm{E} 2=1300 \mathrm{Mpa} \\
\mathrm{h} 2=48 \mathrm{~cm}\end{array}$ & 0.2 & $2400 \mathrm{~kg} / \mathrm{m}^{3}$ \\
\hline groundwork & $\begin{array}{c}\mathrm{E} 0=40 \mathrm{Mpa} \\
\mathrm{h} 3>200 \mathrm{~cm}\end{array}$ & 0.4 & $1800 \mathrm{~kg} / \mathrm{m}^{3}$ \\
\hline
\end{tabular}

Fig. 1 The finite element model

\section{The asphalt pavement vertical stress dynamic analysis under the moving load}

The node position and vertical stress \& time change curve. The model has 43 units in the load moving direction, counting the boundary point all has 44 nodes. As speed $60 \mathrm{~km} / \mathrm{h}$ computing, load action time is $0.18 \mathrm{~s}$. In this article: stress in tension is positive, compression is negative.

Fig. 2 (a) is the load moving direction and passing node diagram, and several representative nodes are chosen in the load moving track. Figure 2 (c) (f) shows the curves of vertical stress with time segment. Fig. 2 (b) is the vertical stress with all the load action time curve of node 3710, the other nodes curves are similar to 3710 , and only the maximum stress time point are different. It is used to contrast with the node vertical stress \& certain time range. 
Analyzing Fig. (b) : the node vertical stress is only on the 0 scale line upper and lower vibration when the load is moved in front of the node 3710 . When the load reaches the node, the node vertical stress increases suddenly. Tensile stress appears, then compressive stress of more 5 times than the tensile stress appears, and later the compressive stress, tensile compressive stresses appear alternately, and reduce gradually.

The vertical stress change laws within some time range. According to the program operating parameters, the time point and the time difference and the node vertical stress of the certain time point, are all shown in Table 2. The vertical stress variation curves of the four nodes in the time of 0.12 to 0.18 s in Fig. 2 (c) (f). The vertical stress of the node 3178, 3402, and 3870 vibrate regularly with time according to sine curve laws. And the node 4074 is different from those because the load acts the node 4074 within 0.12 to 0.18 s, but its overall variation trend is the same as (b).

The curve (c) (e) can be seen in Fig. 2. The node vertical stress still appears tension \& compression status alternately and presents sine curve decreasing after the load acting. It is thus clear that the nodes vertical stress expresses vibration state under the moving load. Passing the same time length after the load acting the node, the vertical stress decreases a little from (c) to (d), but (e) decreases evidently, the relative data are shown in Table 2. Thus as the load moves from the front to the rear, the certain time point vertical stress of the node is also reduced. These is relative to the model constraint condition or is relative to the node vibration characteristic under the moving load probably. Thus, the vertical stress under moving load is more complex than that under static load. In addition, the existing data is insufficient, the paper next effort direction should extract more data from the results of the program to find out more useful laws and to get more accurate conclusion.

Table 2 the time point and the time difference and the node vertical stress

\begin{tabular}{|c|c|c|c|c|}
\hline Node number & node 3178 & node 3402 & node 3710 & node 4074 \\
\hline Load acting time point t1 $\left(\times 10^{-3}\right) \mathrm{s}$ & 8.372 & 41.860 & 87.907 & 142.326 \\
\hline$(0.12-\mathrm{t} 1)\left(\times 10^{-3}\right) \mathrm{s}$ & 111.628 & 78.140 & 32.093 & -22.326 \\
\hline After load passing $111.628 \mathrm{~s}$ time point $(\mathrm{s})$ & 0.120 & 0.153 & 0.199 & - \\
\hline Above time point vertic al stress $(\mathrm{Kpa})$ & 340 & 320 & 100 (estimate) & - \\
\hline
\end{tabular}




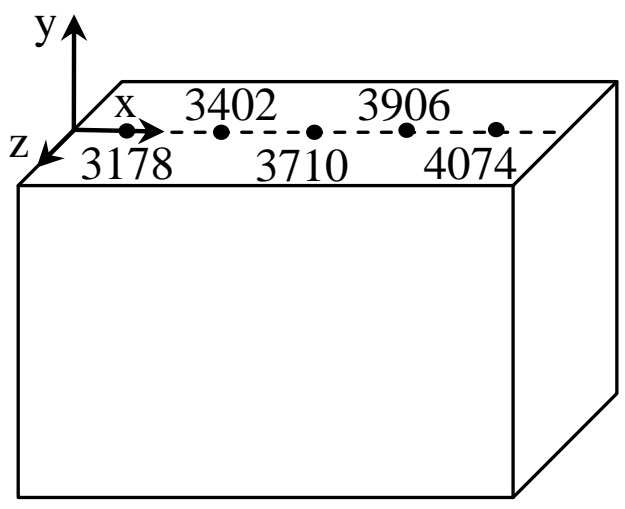

(a) the load moving direction and nodes

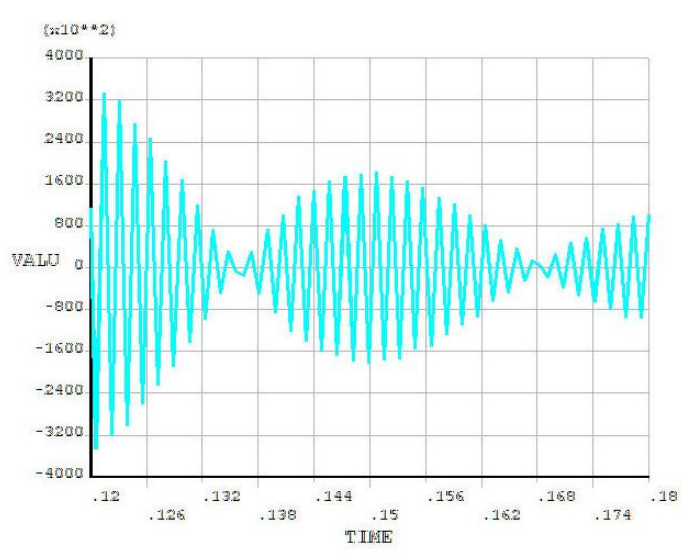

(c) node 3178 的 $\mathrm{SY} \sim$ time curve(0.12-0.18)

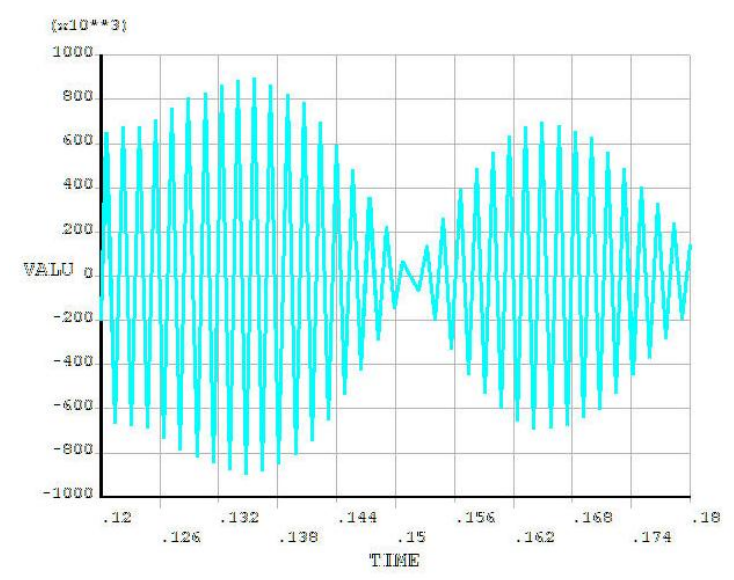

(e) node 3710 的 $\mathrm{SY} \sim$ time curve(0.12-0.18)

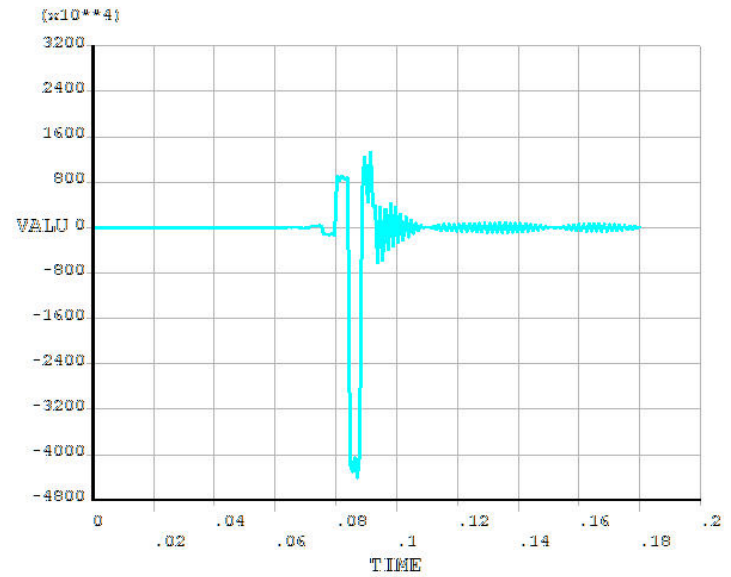

(b) node $3710 \mathrm{SY} \sim$ time curve $(0-0.18)$

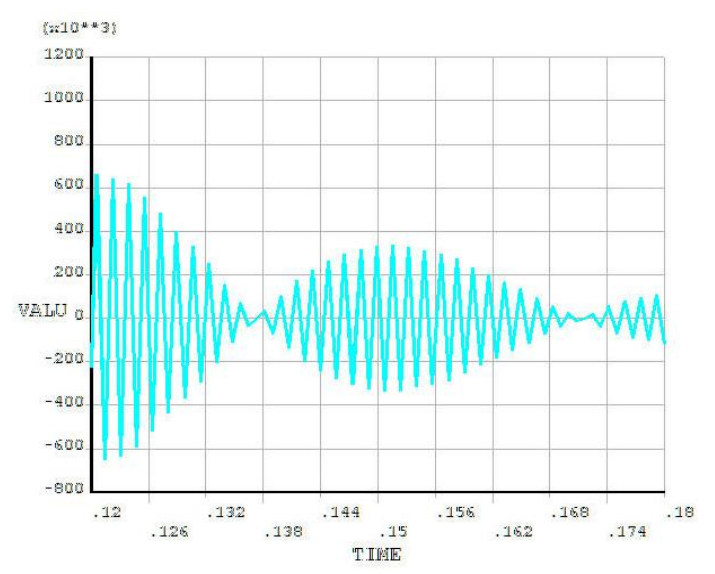

(d) node 3402 的 $\mathrm{SY} \sim$ time curve(0.12-0.18)

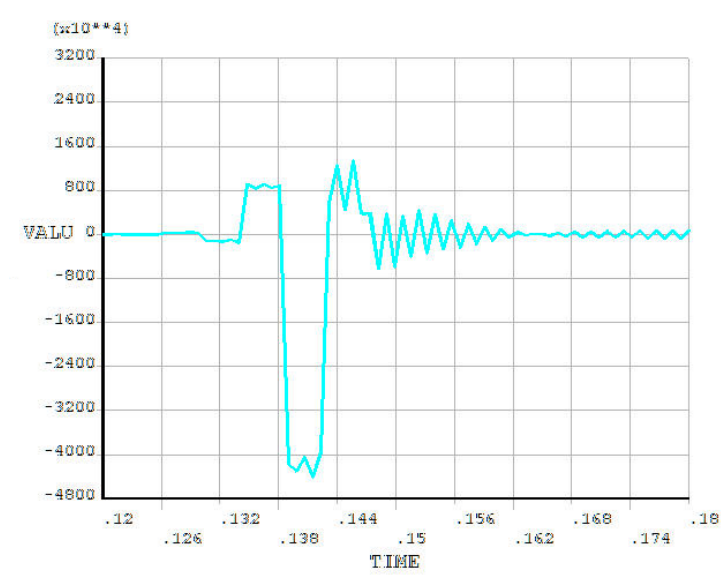

(f) node 4074 的 $\mathrm{SY} \sim$ time curve $(0.12-0.18)$

Fig. 2 some nodes vertical stress (SY) and time curves

\section{Conclusions}

The node vertical stress still appears tension \& compression status alternately and presents sine curve decreasing after the load acting. It is thus clear that the nodes vertical stress expresses vibration state under the moving load. Passing the same time length after the load acting the node, 
as the load moves from the front to the rear, the vertical stress of the node is also reduced. Thus, the vertical stress under moving load is more complex than that under static load.

\section{References}

[1] China calling criterion. Criterion for design of road asphalt concrete pavement. (JTG D50-2006). Beijing: people traffic publishing company, 2006

[2] Xue-jun Deng. Roadbed and road surface engineering [M]. Beijing: people traffic publishing company, 2008.100-120

[3] Ben-guo He. ANSYS civil engineering application examples [M]. Beijing: China water resources and hydropower publishing company, 2011.

[4] Xu-cheng Wang, Min Shao. The finite element fundamental principle and numerical value method [M]. Beijing: Tsinghua University publishing company, 1997. 